\title{
SUPRACONDYLAR FRACTURES OF THE HUMERUS IN CHILDREN
}

\author{
TREATMENT BY STRAIGHT LATERAL TRACTION
}

JAMES PIGGOT, H. KERR GRAHAM, GERALD F. MCCOY

From the Royal Belfast Hospital for Sick Children and The Ulster Hospital

\begin{abstract}
Ninety-eight children with severely displaced supracondylar fractures of the humerus were treated by straight lateral traction. After a mean follow-up period of 3.5 years there were 90 satisfactory and only eight unsatisfactory results. Cubitus varus was present in only four children, which compares favourably with the results of operative treatment. The indications for straight lateral traction, and the advantages of this method, are discussed.
\end{abstract}

Supracondylar fractures of the humerus, the most common elbow injury in children (Blount, Schulz and Cassidy 1951), are noted for complications, including Volkmann's ischaemic contracture, myositis ossificans and permanent nerve lesions (Henrikson 1966). Although these may result in serious loss of function, they are fortunately uncommon. The commonest and most neglected complication is an alteration in the carrying angle of the arm with resultant cubitus varus. Because early management concentrates on avoiding the more serious complications, control of the carrying angle may receive a low priority; this is reflected in a reported change of carrying angle of up to $57 \%$ and averaging $30 \%$ (Smith 1960). Minor increases in the carrying angle, that is, increased valgus, may be acceptable but, if the normal valgus angle is reversed, the ugly deformity of cubitus varus results. This may be a serious cosmetic problem requiring operative correction by supracondylar osteotomy (King and Secor 1951).

Although the extensive literature on this fracture describes many methods of treatment, both conservative and operative, it would appear that no one method is suitable for all fractures, nor has any method gained universal acceptance. Straight lateral traction was first described in 1939: "... so the author decided to use skin traction in the straight lateral position, with the child in bed. To his amazement, the fragments returned to an

J. Piggot, FRCS. Consultant Orthopaedic Surgeon

H. K. Graham. MD, FRCS. Senior Orthopaedic Registrar

Royal Belfast Hospital for Sick Children, 180 Falls Road, Belfast BT12 6BE. Northern Ireland.

G. F. McCoy. MD. FRCS. Senior Orthopaedic Registrar

The Ulster Hospital. Upper Newtownards Road. Dundonald, Belfast BT 160 RH. Northern Ireland.

Requests for reprints should be sent to Mr G. F. McCoy, Department of Orthopaedic Surgery. The Queen`s University of Belfast, Musgrave Park Hospital. Belfast BT9 7JB, Northern Ireland.

c 1986 British Editorial Society of Bone and Joint Surgery $0301620 \times 86 \quad 4084 \$ 2.00$ almost perfect contour of a normal humerus" (Dunlop 1939). Unfortunately, straight lateral traction was modified before it was adequately evaluated. In the later cases described in his original paper. Dunlop adopted a position of increased flexion, with a counterweight above the elbow, in an effort to improve the quality of reduction in the lateral projection. A similar flexed elbow position was used by Allen and Gramse (1945) and by the time the method was committed to textbooks, the flexed position was established (Blount 1954, pp. 26-42).

The flexed elbow position was also adopted by those employing skeletal traction with a transverse Kirschner wire through the ulna (Smith 1947) or an olecranon screw (Palmer et al. 1978). Apart from Dunlop's original paper, three reports in the literature described the treatment of supracondylar fractures in extension; in one of these a plaster cast was used (El-Sharkawi and Fattah 1965), in another a Thomas splint (Bosanquet and Middleton 1983); only Jefferiss (1976) described straight lateral traction with the elbow extended as described in this study.

Many forms of operative treatment also have been described and pinning, after open or closed reduction, is becoming increasingly popular (Ramsey and Griz 1973; Ariño et al. 1977; Weiland et al. 1978; Danielsson and Pettersson 1980). In view of this increasing tendency towards operative fixation, we report the excellent results of straight lateral traction in the treatment of severely displaced supracondylar fractures.

\section{PATIENTS AND METHODS}

From 1977 to 1983, 232 children with supracondylar fractures of the humerus were treated either at the Royal Belfast Hospital for Sick Children or at The Ulster Hospital, Dundonald, Belfast. At a special review clinic, the results of treatment were assessed in 205 children from 1 


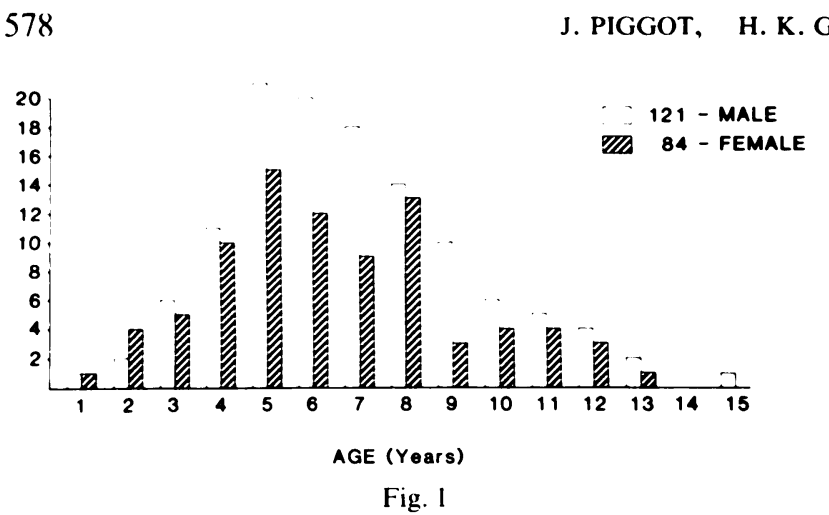

The age sex distribution of 205 supracondylar fractures of the humerus in children.

to 7 years after injury (mean follow-up, 3.5 years); 27 children could not be traced.

The epidemiology of this fracture has been well documented and our study confirms the findings of Lagrange and Rigault (1962) and Henrikson (1966). There was a narrow age range, $85 \%$ of the children being between 4 and 11 years old (Fig. 1); there were also more boys than girls in all age groups except the very young. The non-dominant limb was injured in $63 \%$ of cases. In most patients the fracture was caused by a fall from a height and the peak incidence was during the summer. In 203 children the small distal fragment was displaced posteriorly, the typical extension fracture, while two children had anterior displacement, the much rarer flexion fracture. None had serious associated injuries to the skull or viscera but four children had ipsilateral fractures of the radius and ulna. Grade I compound injuries were present in two children.

Children with these fractures were treated as emergencies, although there were inevitable delays in treating patients who, because of complications, were transferred from other hospitals; these cases comprised a significant percentage of the series ( 41 children, $20 \%$ ) and all had severely displaced fractures. On admission, the neurovascular status of the limb was assessed and radiographs taken. One hundred and seven children $(52 \%)$ were treated by manipulative reduction under general anaesthesia and by immobilisation in flexion, using a collar and cuff worn beneath the clothes.

However, for 98 children $(48 \%)$ this form of treatment was not possible because of neurovascular problems or gross swelling, or because the fracture was irreducible or unstable. Some of the 41 transferred patients had had multiple manipulations under anaesthesia more than once (a practice criticised by Watson-Jones 1952/5), many had a neurovascular deficit on arrival (Table I), and all were grossly swollen; these patients were treated by straight lateral traction with no further attempt at manipulative reduction. In the remaining patients the traction was applied in the operating theatre if there had been failure to obtain reduction, or to hold it, or if neurovascular problems followed initial treatment in flexion.
Table I. Neurovascular complications in 75 of 98 children with supracondylar fractures treated by straight lateral traction

$\left.\begin{array}{lcc}\hline \text { Complication } & \text { Number } & \text { Per cent } \\ \hline \text { Absent radial pulse } & 32 & 33 \\ & & \\ \text { Nerve deficit } & 17 & 17 \\ \quad \begin{array}{l}\text { Median } \\ \quad \text { Uadial }\end{array} & 6 & 6 \\ \quad \text { Ulnar } & 5 & 5\end{array}\right\} 28$

Technique. Skin traction is applied according to Dunlop's original description, that is, with the elbow extended in the straight lateral position (Dunlop 1939). Under anaesthesia or sedation, adhesive tapes are applied to the forearm and held with an elasticated bandage. With the shoulder abducted to 90 , and the elbow supported at between 5 and 10 of flexion, a single cord from the skin-traction set is fed over a pulley on a universal swivel joint to a weight of between 1 and $4 \mathrm{lb}(0.45$ to $1.8 \mathrm{~kg}$ ). The position of the entire apparatus can be moved up or down parallel to the bed so that the carrying angle of the injured arm matches that of the uninjured arm (Fig. 2). This position is best judged with the elbow extended and the forearm supinated and the carrying angle of both arms is checked throughout the period of treatment.

Repeated assessment of the circulation is carried out during the first week in traction. On its own, an absent radial pulse is not an indication for arterial exploration (Blount 1950; Blount et al. 1951); colour, temperature, capillary return of the nail bed, sensation and pain on passive extension of the fingers must all be considered. Most children need only one injection of opiate, followed by oral analgesics; those who need more are considered to have ischaemic pain until proven otherwise.

Nerve palsies are diagnosed in the usual way, although the signs may be hard to elicit in a small child with a painful fracture, and partial lesions are frequent. Inability to flex the interphalangeal joint of the thumb may be the only motor deficit in median nerve lesions, and absence of sweating is a useful guide to sensory loss.

The traction is adjusted according to the carrying angle of the normal arm and the alignment of the distal fragment as seen on the anteroposterior check radiograph (Figs 3 and 4). The lateral radiograph, which may show varying degrees of posterior displacement, is of much less significance.

After two weeks in traction, exercises are encouraged for short periods each day with the traction weight supported on a small table (Fig. 5). After three weeks the traction is removed and the child discharged with instructions about simple active exercises; passive stretching and physiotherapy are forbidden. Frequent 


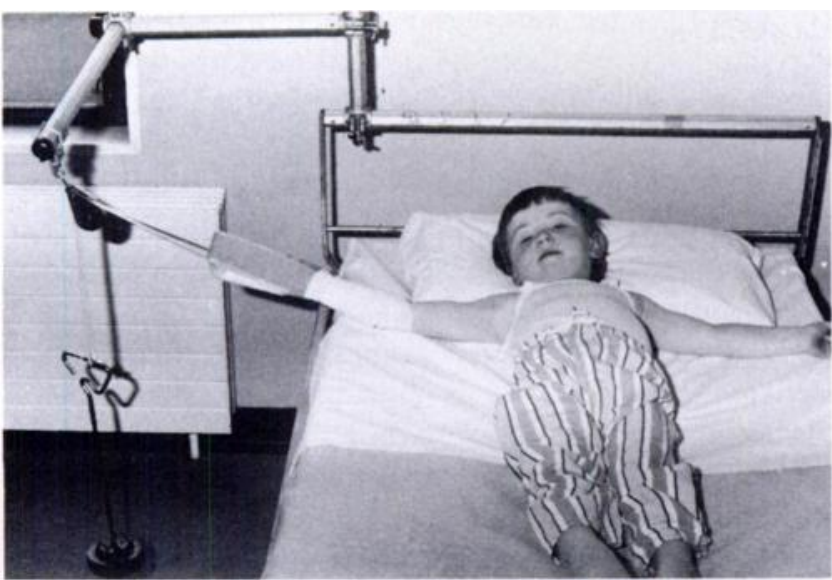

Fig. 2

Treatment of a supracondylar fracture of the humerus by straight lateral traction: the carrying angle of both arms is clearly visible.

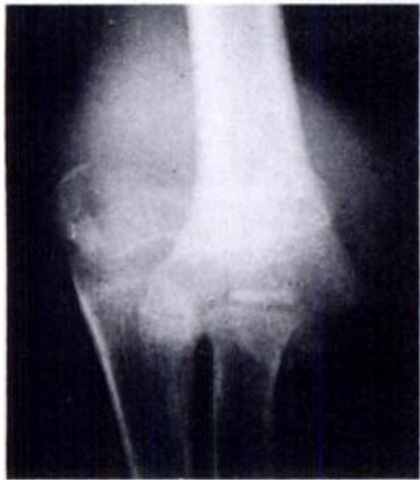

Fig. 3

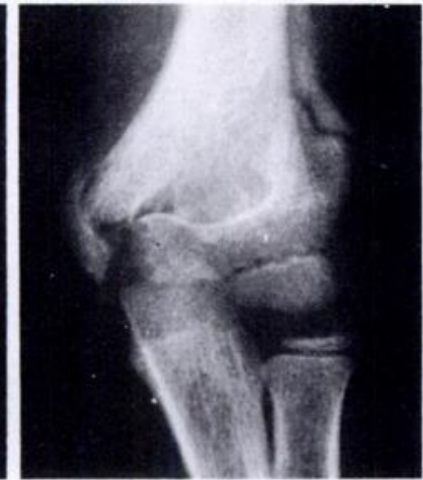

Fig. 4
Anteroposterior radiographs of a patient treated by straight lateral traction. Figure 3 On admission. Figure 4 - At three weeks.

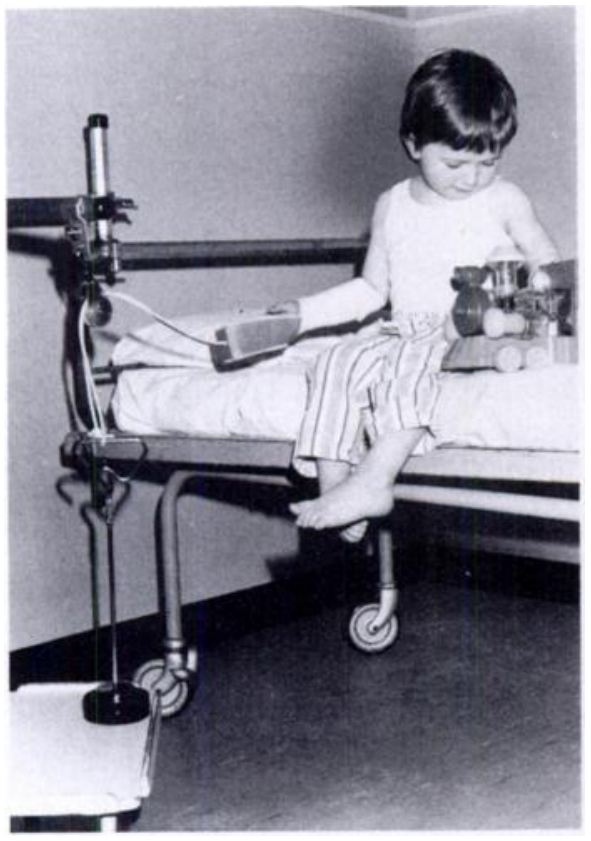

Fig. 5

Active exercises being performed after two weeks in traction. checks are made at the outpatient clinic to assess the return of function. Most children have about $50^{\circ}$ of flexion on discharge, which increases to $90^{\circ}$ in about four weeks. Full flexion is almost invariably regained but the final 30 may be delayed for up to two years, since it depends on remodelling and growth.

Assessment. The severity of injury is graded according to the degree of displacement of the fracture on the original radiograph, using Holmberg's criteria (1945). Grade I are undisplaced or minimally displaced greenstick fractures. Grade II show medial or lateral displacement on the anteroposterior radiograph, with good contact between the fragments on the lateral film. Grade III are characterised by a sharp anterior spike on the lateral film, largely due to rotational displacement. Grade IV are the most severely displaced fractures, with no contact between the proximal and distal fragments on the lateral radiograph.

Grade I and II fractures usually have no neurovascular complications or significant swelling and may be conveniently managed by flexion in a collar and cuff. Grade III and IV fractures, however, often have severe swelling or neurovascular deficit and are not suitable for treatment in flexion; in our series $84 \%$ of fractures were in this group (Table II).

Table II. Radiological classification* and treatment of 205 supracondylar fractures of the humerus

\begin{tabular}{lcc}
\hline & \multicolumn{1}{c}{ Treatment } & \\
\cline { 2 - 3 } Grade & Collar and cuff (flexion) & Traction \\
\hline I & 34 & 0 \\
II & 21 & 3 \\
III & 32 & 44 \\
IV & 8 & 38 \\
Unclassified & 12 & 13 \\
Total & 107 & 98 \\
\hline
\end{tabular}

* Holmberg 1945

We assessed the results by measuring the flexionextension arc and the carrying angle. In some cases, radiographs were taken to assess remodelling but these were not used in grading the results.

The carrying angles of both the injured and the uninjured arms were measured using a long goniometer, with the elbow in extension and the forearm in full supination. The flexion-extension arc in both arms was also measured. Patients were asked about pain, restriction of movement, and satisfaction with the appearance of the arm. If a nerve lesion had been noted originally, a neurological examination was performed.

Of the various grading systems in the literature, the criteria of Flynn (Table III) were adopted as being the most rigorous and precise (Flynn, Matthews and Benoit 1974): function is graded as the restriction of the 
Table III. Grading of results (after Flynn et al. 1974)

\begin{tabular}{lcc} 
Result & $\begin{array}{l}\text { Function } \\
\text { (loss of } \\
\text { flexion-extension) }\end{array}$ & $\begin{array}{l}\text { Change in } \\
\text { carrying angle }\end{array}$ \\
Excellent & 0 to 5 & 0 to 5 \\
Good & 6 to 10 & 6 to 10 \\
Fair & 11 to 15 & 11 to 15 \\
Poor & Over 15 & Over 15 \\
\hline
\end{tabular}

flexion-extension arc, and appearance as the change in the carrying angle. The lower of the two grades scored is adopted. Any elbow with a reversed or varus carrying angle is automatically graded as poor, even if the carrying angle change is less than 5 . Some children were noted to have a cubitus rectus ( 0 carrying angle), or only a few degrees of valgus, in the normal arm. A small change in the carrying angle in such cases may lead to a varus elbow, and, by definition, a poor result.

All patients were assessed by one of the authors at least one year after injury. The mean follow-up was 3.5 years, with a range of 1 to 7 years. Despite the relatively high incidence of an absent radial pulse on admission, there were no cases of Volkmann's ischaemic contracture. No child had exploration of the brachial artery and all had a normal peripheral circulation at follow-up. The nerve lesions were treated expectantly and all recovered fully, with the exception of one partial radial palsy.

\section{RESULTS}

The results, as assessed by Flynn's criteria, are given in Table IV. Superficially, there is little difference between the results of treatment in flexion using a collar and cuff, or treatment in extension with traction. However, references to Table II will show that the collar-and-cuff group had less severe fractures than those treated in traction.

Table IV. Results of assessment. comparing two methods of treatment in 205 fractures (after Flynn et al. 1974)

\begin{tabular}{lcc} 
Result & Collar and cuf & Traction \\
\hline Excellent & 64 & 64 \\
Good & 24 & 20 \\
Fair & 8 & 6 \\
Poor & 11 & 8 \\
Total & 107 & 98 \\
$\begin{array}{l}\text { Cubitus varus } \\
\text { (for Grade III and } \\
\text { IV fractures) }\end{array}$ & $10(4.9 \%)$ & $4(1.9 \%)$ \\
\hline
\end{tabular}

Whereas more than half the collar-and-cuff group were Grade I and II fractures, almost all the traction group were Grades III and IV. The cubitus varus rate for Grade
III and IV fractures treated in a collar and cuff was $25 \%$, as against $4 \%$ for those treated in traction. In this traction group, 90 patients were assessed as satisfactory and eight as unsatisfactory.

An explanation of the poor results is given in Table V. Five children had a restriction of the flexionextension arc of more than 15 . Three of these had a relatively short follow-up ( 12 to 15 months) and may well improve; two others had a second elbow fracture. There were five elbows graded as poor due to a changed carrying angle; three of these were children with small carrying angles on the uninjured side (less than 5 ) who ended up with mild cubitus varus $(2,4,4)$. Two children had a major carrying-angle change (one varus, one valgus) and they required osteotomy.

In the uninjured elbows, the mean carrying angle was 7.5 (range 2 to 16 ). The mean flexion was 142 (range 132 to 155 ), while the mean extension was to -7 (range 0 to -20 ). In the injured elbows, although the mean carrying angle was reduced by $0.5^{\circ}$ to $7^{\circ}$, the range widened considerably to between 16 varus and 26 valgus. Mean flexion was reduced to 135 (range 110 to 150 ) while extension increased to a mean of -10 (from -25 to $+12^{\circ}$ ), that is, while recurvatum was increased by 3 , the total flexion-extension arc was reduced by an average of 4 .

Table V. Reasons for poor results of traction in eight patients*

\begin{tabular}{ll}
\hline Cause & Number \\
$>15$ loss of flexion extension & $5(16$ to 28$)$ \\
Valgus & $1(26)$ \\
Varus & $4(2$ to 16$)$ \\
Residual nerve palsy (radial) & 1 \\
\hline $\begin{array}{l}\text { * Some results were graded poor on more } \\
\text { than one criterion }\end{array}$
\end{tabular}

\section{DISCUSSION}

Treatment of supracondylar fractures of the humerus in flexion with a collar and cuff has a long history in the English literature, and was recommended and taught by such authorities as Astley Cooper (1826), Robert Jones (1921), Watson-Jones (1952/5) and Charnley (1961). It is widely accepted as the ideal outpatient treatment for undisplaced or minimally displaced fractures and may also be used for displaced fractures if reduction is achieved before swelling supervenes.

However, in the presence of gross displacement associated with severe swelling or a neurovascular deficit, we concur with Blount that the method has "nothing to commend it" (Blount et al. 1951). Even if reduction is achieved, the elbow often has to be extended beyond 90 because of loss of the radial pulse. In such a position, the stabilising effect of the triceps and posterior periosteum 


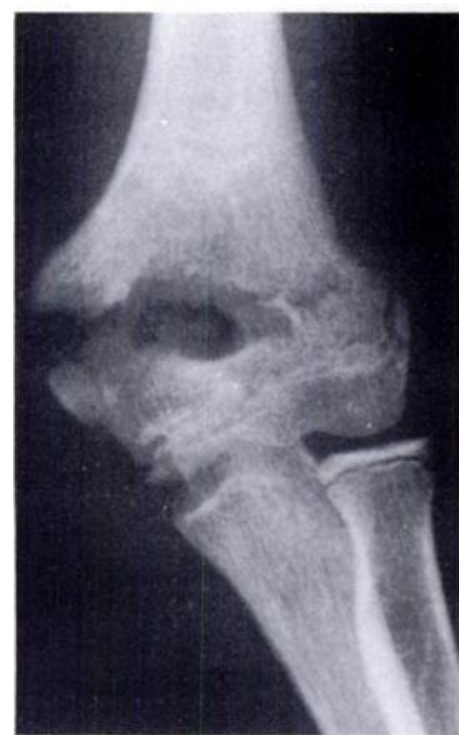

I:ig. 6

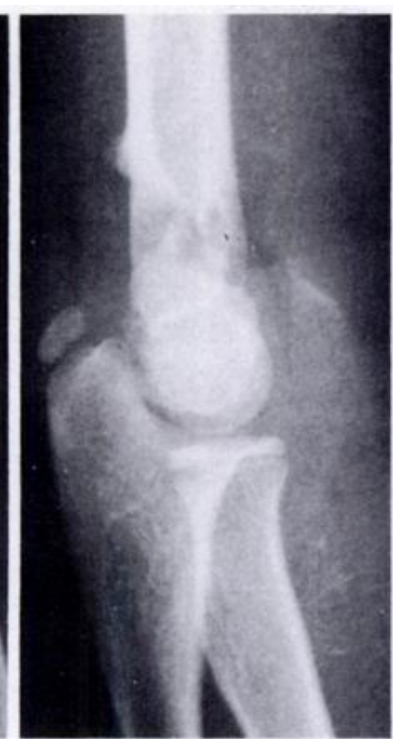

Fig. 7

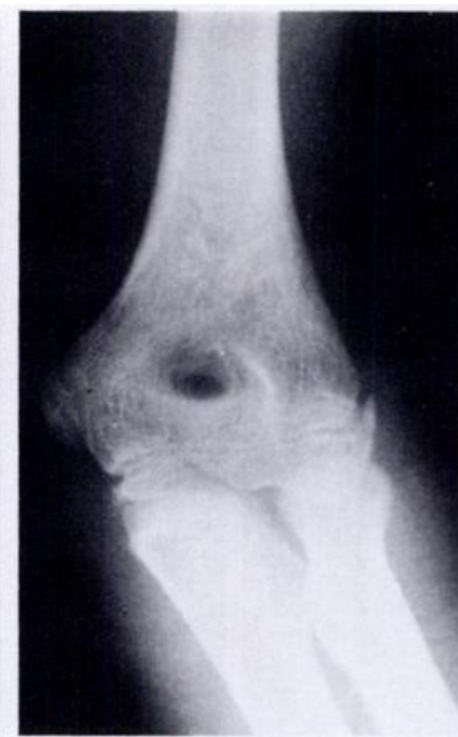

Fig. 8

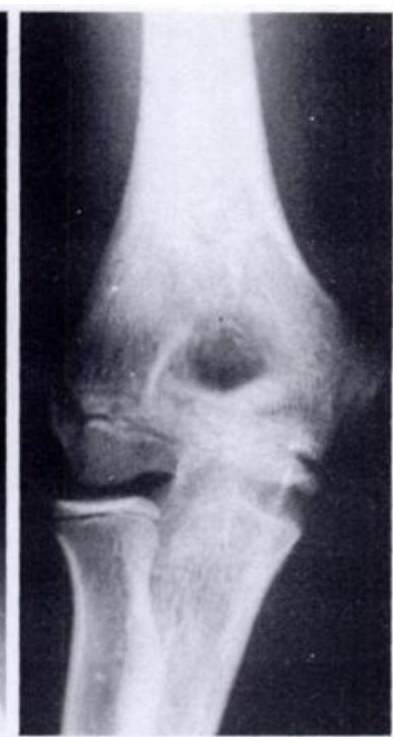

Fig. 9

Figures 6 and 7 Grade 11 fracture with lateral impaction. giving a valgus tilt. Figure 8 - At review. The increased carrying angle is compared with the uninjured side (Fig. 9): note that the alignment has not altered since injury a poor result.

is lost: redisplacement and cubitus varus may then occur (D'Ambrosia 1972). This is the "supracondylar dilemma“: flexion stabilises the fracture but compromises the circulation (Rang 1974). In our study, 10 out of 41 Grade III and IV fractures treated in flexion had cubitus varus $(25 \%)$, and in six of these children the deformity required corrective osteotomy.

Charnley has pointed out that the mechanical effect of flexing a swollen elbow is to increase pressure in the cubital fossa (Charnley 1961, p 108) but, in the extended position. pressure is reduced by allowing the contents of the cubital fossa to occupy a greater volume. However, permanent lesions of the median, radial or ulnar nerves are sometimes due to incorporation in callus, an event which seems only to occur in flexion (Post and Haskell 1974: Symeonides. Paschaloglou and Pagalides 1975; Lalanandham and Laurence 1984). Acute flexion should therefore be avoided in the presence of neurovascular deficit.

Faced with these difficulties, what are the alternatives. Open reduction and internal fixation has been recommended by some authors (Ramsey and Griz 1973; Shifrin. Gehring and Iglesias 1976: Weiland et al. 1978) but condemned by many (Watson-Jones 1952/5; Attenborough 1953: Mitchell and Adams 1961; Mann 1963). Permanent stiffness was common after the posterior approach described by Sandegård (1943-4), though more recent reports suggest that a limited medial approach affords better results in this respect (Ramsey and Griz 1973: Danielsson and Pettersson 1980). Closed reduction and percutaneous pinning avoids the risk of stiffness associated with open operation but increases the risk of damage to the ulnar nerve. The proponents of both methods agree. however, that a high degree of technical skill and experience are necessary (Flynn et al. 1974;
Shifrin et al. 1976). Since the functional results of traction are good, operative treatment should have significant advantages to justify the risks.

Control of the carrying angle is the most important criterion in assessing methods of treatment. Variable results have been reported with Dunlop traction in the flexed-elbow position, with a cubitus varus rate of up to $60 \%$ (Carcassonne. Bergoin and Hornung 1972). largely because radiographs of the reduction in traction are difficult to interpret. Displacement is easily seen but this is less important than alignment. The distal fragment is small and errors of alignment of 5 to 10 are difficult to recognise but sufficient to cause cubitus varus. Smith (1960) has confirmed that medial tilt of the small distal fragment is the only displacement responsible for cubitus varus. Medial rotation is often accompanied by medial tilt. Rotation predisposes to medial tilt (because the distal fragment is unsupported), but it is not the cause of cubitus varus per se.

Skeletal traction aims to control the tendency of the distal fragment to tilt into varus. Traction using a transverse Kirschner wire has a high complication rate with an appreciable incidence of ulnar nerve lesions, infection. and cutting out (Smith 1947). An olecranon screw has fewer complications and probably provides better control (Worlock and Colton 1984).

Clinical and radiological methods have been described in an attempt to assess alignment during treatment in flexion, including Baumann's angle (Dodge 1972) and the direct observation method of Smith (1967). We nonetheless share Nacht's reservation that Baumann's angle is inaccurate in younger children (Nacht et al. 1983). Direct observation of the bony landmarks as advocated by Smith is also impractical in many of the grossly swollen elbows we have encountered. 

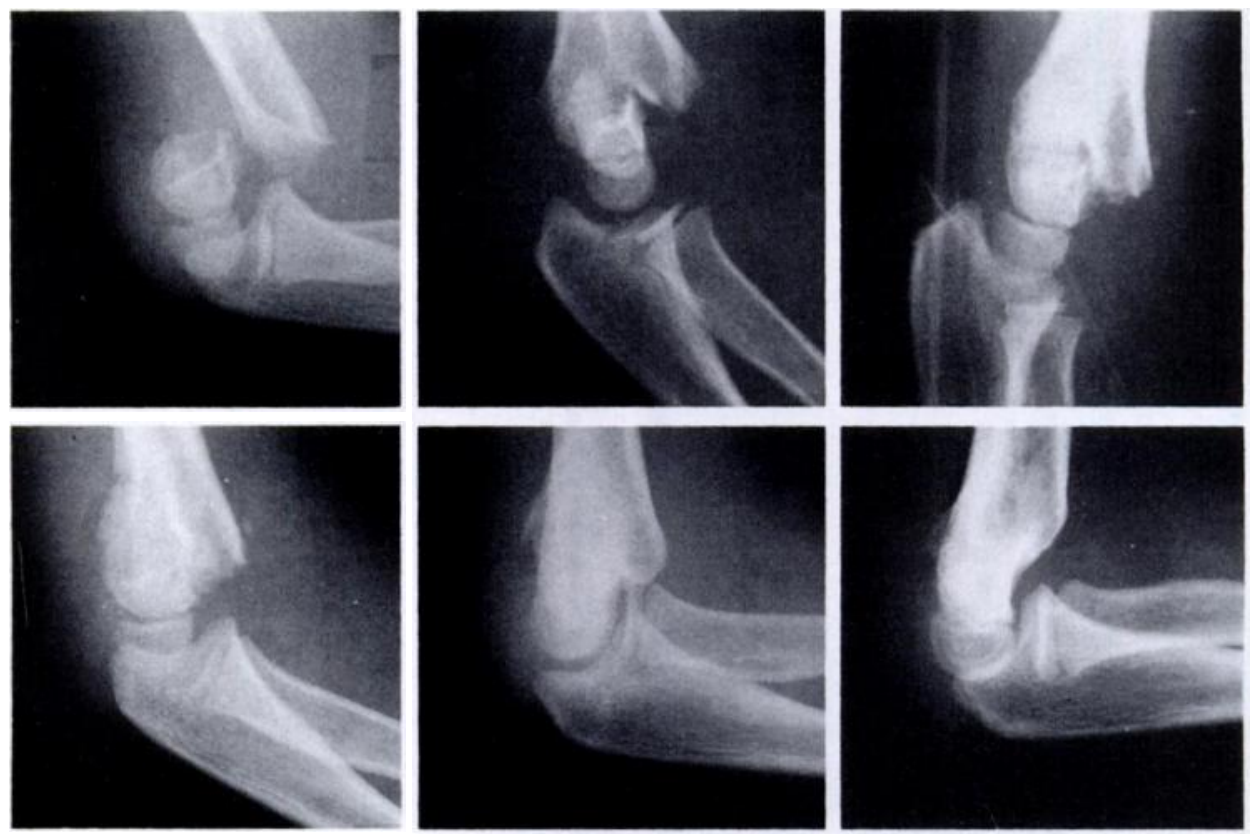

Fig. 10

Remodelling seen in serial lateral radiographs of one patient. Above, position on admission. after attempted reduction (the pulse disappeared on elbow flexion), and in traction. Below, the appearance after three weeks traction (flexion only 50) at three months (flexion 100 ) and at one year (flexion full).

With all forms of treatment in flexion, the carrying angle is not seen until full extension of the elbow is regained, often months after injury. The unique advantage of treatment in extension is that the carrying angle is visible throughout the period of treatment, and alterations can be made before it is too late. To achieve increased control over the final carrying angle one must accept some degree of residual posterior displacement, and possibly residual rotational deformity.

Using straight lateral traction for the severe and often complicated fractures, we found control of the carrying angle to be excellent in most patients. There were, however, two who had major changes in the carrying angle; both had impacted Grade II fractures (Figs 6 and 7). Treatment of impacted fractures by traction alone is not recommended because the distal fragment is not free to realign (Figs 8 and 9).

Residual posterior displacement associated with treatment in extension is corrected by growth and remodelling. Thus, dogmatic statements, such as "an accurate anatomical reduction is essential for a perfect result" are clearly not true. Residual displacement is corrected by remodelling which is maximal near a joint and in the plane of movement of that joint (Blount 1954 . pp. 26-42). Applied to the elbow, this means that posterior displacement will remodel; tilt, however, will not.

Attenborough (1953) has drawn attention to the fact that marked residual displacement is compatible with good function. In some of our cases we have judged that further manipulation was contra-indicated and have accepted the residual posterior displacement; this has not compromised the end-result. Posterior displacement of the distal fragment may result in a block to flexion anteriorly, but this resolves by a combination of remodelling and growth (Fig. 10). Full flexion is almost invariably regained though it may take up to three years to do so. Because treatment in extension relies on remodelling, there is obviously an upper age limit for this method. The growth plate closes at about the age of 14 years, and at least two years' growth and remodelling should be available to overcome any residual deformity. Fortunately, supracondylar fractures of the humerus are uncommon after the age of 12 (see Fig. 1).

The chief disadvantage of traction is the duration of inpatient treatment, which is usually two to three weeks. However, only one-quarter of supracondylar fractures need this treatment; the higher incidence in our series was due to the transfer of complicated cases from other hospitals and still resulted in only seven cases per year which were treated by traction in each hospital. Worlock and Colton (1984) estimated that there were only two cases of severely displaced fractures per year in the average district general hospital, and that it is thus difficult for junior staff to gain experience in their operative treatment. By contrast, straight lateral traction has three advantages: it is simple and requires no special equipment; it is safe in that Volkmann's ischaemia, permanent nerve lesions, and stiffness are avoided; and finally, control of the carrying angle compares well with the best results of other methods. 


\section{REFERENCES}

Allen PD, Gramse AE. Transcondylar fractures of the humerus treated by Dunlop traction: report of 21 cases. Am J Surg 1945;67: 21727

Ariño VL, Lluch EE, Ramirez AM, Ferrer J, Rodriguez L, Baixauli F. Percutaneous fixation of supracondylar fractures of the humerus in children. J Bone Joint Surg [Am] 1977:59 A:914-6.

Attenborough CG. Remodelling of the humerus after supracondylar fractures in childhood. $J$ Bone Joint Surg $[B r]$ 1953:35- B:386-95.

Blount WP. Schulz I, Cassidy RH. Fractures of the elbow in children. J.A.M.A 1951:146:699 704.

Blount W P. Fractures in children. Baltimore: Williams \& Wilkins, 1954.

Blount WP. Editorial. Volkmann`s ischaemic contracture. Surg Gynecol Ohstet 1950:90:244 6.

Bosanquet JS, Middleton RW. The reduction of supracondylar fractures of the humerus in children treated by traction-in-extension: a review of 18 cases. Injury 1983:14:373 80 .

Carcassonne M, Bergoin M, Hornung $H$. Results of operative treatment of severe supracondylar fractures of the elbow in children. $J$ Pédiatr Surg 1972:7:676 9.

Charnley J. The closed treatment of common fractures. 3rd ed. Edinburgh and London: E \& S Livingstone, 1961.

Cooper Sir A. A treatise on dislocations and on fractures of the joints. 5th ed. London: Longman. 1826.

D'Ambrosia RD. Supracondylar fractures of the humerus: prevention of cubitus varus. J Bome Joint Surg $[A m]$ 1972:54-A:60-6.

Danielsson L, Pettersson H. Open reduction and pin fixation of severely displaced supracondylar fractures of the humerus in children. Acta Orthop Scand 1980:51:249-55.

Dodge HS. Displaced supracondylar fractures of the humerus in children: treatment by Dunlop's traction. J Bone Joint Surg $[\mathrm{Am}]$ 1972:54 A:1408 18

Dunlop J. Transcondylar fractures of the humerus in childhood. $J$ Bone Joint Surg 1939:21:59 73

El-Sharkawi AH, Fattah HA. Treatment of displaced supracondylar fractures of the humerus in children in full extension and supination. J Bone Joint Surg [Br] 1965;47-B:273-9.

Flynn JC. Matthews JG, Benoit RL. Blind pinning of displaced supracondylar fractures of the humerus in children: sixteen years experience with long-term follow-up. J Bone Joint Surg [Am] 1974: 56 A : 26372

Henrikson B. Supracondylar fracture of the humerus in children: a late review of end-results with special reference to the cause of deformity. disability and complications. Acta Chir Scand 1966:Suppl 369: 172.

Holmberg L. Fractures of the distal end of the humerus in children. Acta Chir Scand 1945:92, Suppl 103: 1-69.

Jefferiss CD. Straight lateral traction in selected supracondylar fractures of the humerus in children. Injury 1976:8:213-20.
Jones R, ed. Orthopaedic surgery of injuries. Vol. I. London: H. Frowde; Hodder \& Stoughton, 1921.

King D, Secor C. Bow elbow (cubitus varus). J Bone Joint Surg $[\mathrm{Am}]$ 1951;33 A:572-6.

Lagrange J, Rigault P. Fracture supra-condyliennes. Re'v (hir Orıhop 1962:48:337 414 .

Lalanandham T, Laurence WN. Entrapment of the ulnar nerve in the callus of a supracondylar fracture of the humerus. Injury 1984:16: 129-30.

Mann TS. Prognosis in supracondylar fractures. J Bone Joint Surg $[\mathrm{Br}]$ 1963:45 B:516 22.

Mitchell WJ, Adams JP. Supracondylar fractures of the humerus in children: a ten-year review. JAMA 1961:175:5737.

Nacht JL, Ecker ML, Chung SMK, Lotke PA, Das M. Supracondylar fractures of the humerus in children treated by closed reduction and percutaneous pinning. Clin Orthop 1983:177:203 9.

Palmer EE, Niemann KMW, Vesely D, Armstrong JH. Supracondylar fracture of the humerus in children. J Bome Joint Surg $[\mathrm{Am}]$ 1978: 60- A:653 6

Post M, Haskell SS. Reconstruction of the median nerve following entrapment in supracondylar fracture of the humerus: a case report. J Trauma 1974:14:252 64.

Ramsey RH, Griz J. Immediate open reduction and internal fixation of severely displaced supracondylar fractures of the humerus in children. Clin Orthop 1973:90:130 2.

Rang M. Children's fractures. 2nd ed. Philadelphia: JP Lippincott, 1974.

Sandegård E. Fracture of the lower end of the humerus in children: treatment and results. Acta Chir Scand 1943 4:89:1 16

Shifrin PG, Gehring HW, Iglesias LJ. Open reduction and internal fixation of displaced supracondylar fractures of the humerus in children. Orthop Clin North Am 1976:7(3):573 81.

Smith FM. Kirschner wire traction in elbow and upper arm injuries. Am J Surg 1947:74:770-87.

Smith L. Deformity following supracondylar fractures of the humerus. $J$ Bone Joint Surg $[A m]$ 1960:42 A:235 52.

Smith L. Supracondylar fractures of the humerus treated by direct observation. Clin Orthop 1967:50:37 42.

Symeonides PP, Paschaloglou C, Pagalides T. Radial nerve enclosed in the callus of a supracondylar fracture. J Bone Joint Surg $[B r] 1975$ : 57. B: 5234

Watson-Jones R. Fractures and joint injuries. 4th ed. Edinburgh: E \& S Livingstone. 1952,5.

Weiland AJ, Meyer S, Tolo VT, Berg HL, Mueller J. Surgical treatment of displaced supracondylar fractures of the humerus in children analysis of fifty-two cases followed for five to fifteen years. J Bone' Joint Surg $[\mathrm{Am}]$ 1978:60 A:657 61 .

Worlock PH, Colton CL. Displaced supracondylar fractures of the humerus in children treated by overhead olecranon traction. Injury. 1984:15:316-21. 